\title{
Estrogen And Progesterone Receptors In Dysfunctional Uterine Bleeding
}

\author{
Dr. V. Kalyan Chakravarthy M.D ${ }^{1}$, Dr. Usha Nag M.D ${ }^{2}$, \\ Dr. D. Ranga Rao M.D ${ }^{3}$, Dr. A.M. Anusha ${ }^{4}$ \\ ${ }^{I}$ (Department of Pathology, Dr. Pinnamaneni Siddhartha Institute of Medical Sciences \& R.F, INDIA) \\ ${ }^{2}$ (Department of OBG, Dr. Pinnamaneni Siddhartha Institute of Medical Sciences \& R.F, INDIA) \\ ${ }^{3}$ (Department of Pathology, Dr. Pinnamaneni Siddhartha Institute of Medical Sciences \& R.F, INDIA) \\ ${ }^{4}$ (Department of Pathology, Dr. Pinnamaneni Siddhartha Institute of Medical Sciences \& R.F, INDIA)
}

\begin{abstract}
Objective: To analyze estrogen and progesterone receptors $(E R, P R)$ in various histopathological patterns in relation to circulating estradiol levels in patients with dysfunctional uterine bleeding.

Material Methods: 60 patients diagnosed to have dysfunctional uterine bleeding (DUB) were studied. All of them had increased amount of bleeding during menses. Any case with a known cause of bleeding was not included in the study. A strict criterion for the definition of DUB was maintained. Serum estradiol levels were estimated by Immunoflorescence technique. Dilatation and curettage was done and sent for histopathological examination and immunohistochemistry for estrogen and progesterone receptors. The histopathology report was correlated with the estradiol levels and ER, PR status.

Result: Estradiol levels were increased in disordered proliferation, simple cystic hyperplasia and irregular ripening and very high in complex adenomatous hyperplasia and were high normal in patients diagnosed as proliferative phase and secretory phase. In this study ER and PR levels were increased in hyperplasias and endometrial carcinomas.

Conclusion: Estradiol levels were high in patients with dysfunctional bleeding and range varied according to different levels of hyperplasia and is a useful parameter to establish the etiology and in treatment.
\end{abstract}

Key words: disordered proliferation, dysfunctional bleeding, estradiol.

\section{Introduction}

About $90 \%$ of cases of DUB are anovulatory and $10 \%$ ovulatory $^{1}$. During an anovulatory cycle, the corpus luteum does not form. Thus, the normal cyclical secretion of progesterone does not occur, and estrogen stimulates the endometrium unopposed ${ }^{2}$. Without progesterone, the endometrium continues to proliferate, eventually outgrowing its blood supply; it then sloughs and bleeds incompletely, irregularly, and sometimes profusely or for a long time. When this abnormal process occurs repeatedly, the endometrium can become hyperplastic, sometimes with atypical or cancerous cells ${ }^{3}$. Anovulatory DUB can result secondary to PCOS and hypothyroidism ${ }^{4}$.

An acute bleeding episode is best controlled with high-dose estrogen. Treatment of chronic, repetitive, bleeding problems may consist of hormonal therapy with estrogen and progestin or cyclical progestin alone. Surgery may be needed if hormone therapy fails. Surgical options include dilation and curettage (D\&C), laser or electrocauterization, endometrial ablation, or hysterectomy ${ }^{4}$. Circulating blood levels of estrogen and progesterone have implications on DUB ${ }^{7}$. A few studies have shown that DUB has high estradiol levels ${ }^{8}$. The estrogen receptor (ER) and progesterone receptor (PR) expression and distribution pattern might play an important role in normal endometrial function. Receptor studies in DUB cases show that ER and PR levels in DUB patients were significantly higher ${ }^{8}$. Morphometric analysis included gland shape, lumen/gland relative volume, gland: stroma ratio and number of capillaries $/ \mathrm{mm}^{2}$ stroma ${ }^{9}$.

In this study we have evaluated the histopathological features of endometrium in correlation with hormone levels and with special emphasis on receptors and morphometry in the diagnosis of menorrhagia.

\section{Material And Methods}

The present study is a one year prospective study carried out in our hospital. The material for the present study was collected from patients who attended Department of Obstetrics and Gynecology and diagnosed clinically to have dysfunctional uterine bleeding. The selection criteria included a meticulous examination to rule out any known cause of excessive bleeding, thus strictly adhering to the definition of DUB. All the patients were subjected to Ultra sonogram to rule out any known pathology. Dilatation and curettage was done under local anesthesia and material sent for histopathological study with complete clinical details. The same day blood was collected for estradiol estimation. Serum estradiol levels were estimated by 
Immunoflorescence technique. The histopathology report was then correlated with the estradiol levels. Estimation of ER \& PR receptors were done using leica reagents. Morphometric analysis of glands and stroma were done with appropriate controls. The results of histopathology, LMP, Estradiol levels, special stains and ER, PR receptors were correlated and analyzed to conclude the cause of menorrhagia. The analyzed data was compared with other series in literature and discussed.

The data is tabulated and analysed using Chi-Square test. $\mathrm{P}$ value of $<0.05$ is considered as statistically significant.

\section{Results}

The study was conducted on 60 patients clinically diagnosed as DUB. The age group of these patients ranged from 22 years to 60 years with maximum number of cases in the range of 31 to 40 years (54.1\%). Only $5.8 \%$ were found to be more than 50 years. The common symptom is menorrhagia with $53.3 \%$. Dilatation and curettage was performed on $84 \%$ of patients. The common histopathologic diagnosis being proliferative phase in $40 \%$ and Disordered proliferative endometrium in $13.3 \%$. Of these $41.6 \%$ and $75 \%$ did not correlate with LMP respectively. Secretory enodometrium was seen in 31.6\%. in the age group of $25-45 \mathrm{yrs}$. $60 \%$ did not correlate with LMP. Irregular ripening was seen in $3.3 \%$ of patients in the age group of $35-40 \mathrm{yrs}$. Simple cystic hyperplasia was seen in $10 \%$ of the patients in the age group of 35-52yrs. Complex hyperplasia was seen in $1.6 \%$. Estradiol levels are markedly increased in complex hyperplasia with more than $120 \mathrm{pg} / \mathrm{ml}$, in simple endometrial hyperplasia and disordered proliferation of endometrium majority had estradiol levels in the range of $81-100 \mathrm{pg} / \mathrm{dl}$. Estrogen receptor levels in stroma and glands was given separate scores based on positivity $(0-25 \%=1,26-50 \%=2,51-75 \%=3,76-100 \%=4)$ and the sum of the both scores obtained was expressed. Progesterone receptor in stroma and glands was given separate scores based on positivity $(0-25 \%=$ $1,26-50 \%=2,51-75 \%=3,76-100 \%=4)$ and the sum of the both scores obtained was expressed.

Mitotic index $(0-5=1+, 6-10=2+, 11-15=3+, 16-20=4+$ and $>20=5+)$ was increased in disordered proliferation, simple endometrial hyperplasia and very high in complex endometrial hyperplasia and endometrial carcinoma.

Gland: stroma ratio was very high in simple endometrial hyperplasia, complex endometrial hyperplasia and endometrial carcinoma.

The most common glands seen were cylindrical. Simple endometrial hyperplasia, complex endometrial hyperplasia and endometrial carcinoma had ramified glands.

Simple endometrial hyperplasia, complex endometrial hyperplasia and endometrial carcinoma had increased lumen/gland relative volume and showed increased number capillaries $/ \mathrm{mm}^{2}$ stroma.

\section{Discussion}

Menstrual disorders are common, accounting for almost 3\% of all outpatient referrals and over $20 \%$ of referrals to gynecology outpatients' clinics. ${ }^{1}$ In this study the maximum age incidence of patients suffering from menorrhagia was between 31-40 years. Pilli GS et $\mathrm{al}^{2}$, Madiha Sajjad ${ }^{3}$ et al and Archana ${ }^{4}$ et al reported that the common age incidence was between 40-50 years, while Sadia Khan ${ }^{5}$ et al reported as 45-55, Shazia Riaz et al ${ }^{6}$ as $45-50$ and Layla et $\mathrm{al}^{7}$ more then 52 .

\begin{tabular}{|c|c|}
\hline Studies done & Age incidence \\
\hline Sadia Khan $^{5}(2011)$ & $45-55$ \\
\hline $\operatorname{Layla}^{7}(2011)$ & $>52$ \\
\hline Madiha Sajjad $^{3}$ (2011) & $40-50$ \\
\hline Shazia Riaz $^{6}$ (2010) & $45-49$ \\
\hline $\operatorname{Archana}^{4}(2010)$ & $40-50$ \\
\hline Present study & $31-40$ \\
\hline
\end{tabular}

In this study the most common pattern seen was proliferative phase (40\%). Pilli GS et $\mathrm{al}^{2}$ reported endometrial hyperplasia as most common (44\%), while Sadia Khan et al ${ }^{5}$ reported proliferative phase (46\%), Shazia Riaz ${ }^{6}$ $(33 \%)$, Archana et $\mathrm{al}^{4}(53 \%)$. Layla et $\mathrm{al}^{7}$ reported secretory phase in $24 \%$ of cases.

\begin{tabular}{|c|c|c|}
\hline Studies done & Endometrial patterns & Percentage \\
\hline Sadia Khan $^{5}(2011)$ & Proliferative phase & 46 \\
\hline $\operatorname{Layla}^{7}(2011)$ & Secretory phase & 24 \\
\hline Shazia Riaz ${ }^{6}(2010)$ & Proliferative phase & 33 \\
\hline $\operatorname{Archana}^{4}(2010)$ & Proliferative phase & 53 \\
\hline Present study & Proliferative endometrium & 40 \\
\hline
\end{tabular}


In this study serum estradiol levels were high in simple endometrial hyperplasia and complex endometrial hyperplasia and very high in endometrial carcinoma. Vysotskiı̌ MM et al ${ }^{8}$ reported high estradiol levels were detected in the blood sera of patients with glandular cystic polyps, atypical and glandular hyperplasia. Gorchev $\underline{\mathrm{G}}^{9}$ et al found normal and decreased estradiol levels in atypical hyperplasia and endometrial carcinoma. Lépine $\underline{\mathrm{J}}$ et $\mathrm{al}^{10}$ stated that circulating levels of estradiol levels were significantly higher in endometrial carcinoma compared to normal endometrium. Mülayim $\mathrm{B}^{11}$ et al reported serum estradiol levels were significantly higher in perimenopausal women with menometrorrhagia. Moen $\mathrm{MH}^{12}$ et al stated that estradiol levels are increased in perimenopausal women with menometrorrhagia.

In this study PAS stain didn't show any advantage when compared to $\mathrm{H} \& \mathrm{E}$. Hong Yul Choi ${ }^{13}$ et al reported that secretory substance in the epithelial cells of the endometrial glands during the secretory phase and menstrual phase was mainly glycogen and concluded that PAS staining is superior to routine hematoxylin and eosin staining for the detection of epithelial secretory substance. Eddie $\mathrm{SM}^{14}$ et al stated that PAS stain is superior to $\mathrm{H} \& \mathrm{E}$.

In this study mitotic index, gland: stroma ratio, lumen/gland relative volume and number of capillaries/mm2 stroma were increased in simple, complex endometrial hyperplasia and endometrial carcinoma. Dunton $\mathrm{C}^{15}$ et al reported that simple endometrial hyperplasia have few mitoses, increased number of glands relative to stroma. In complex endometrial hyperplasia mitoses are typically present; the gland-to-stroma ratio is higher compared to simple hyperplasia. Kendal $\mathrm{BS}^{16}$ et al stated that endometrial carcinoma showed high gland: stroma ratio and increased mitoses. Elyzabeth Avvad ${ }^{17}$ et al reported that volume density was greater in simple hyperplasia than in proliferative endometrium. In simple hyperplasia the glands usually have a tendency to be crowded and with great diameters (luminal dilatation). Baak ${ }^{18}$ et al stated that volume density decreases in atypical hyperplasia and well-differentiated adenocarcinoma of the endometrium.

In this study ER and PR levels were increased in hyperplasias and endometrial carcinomas. Spona $\mathrm{J}^{19}$ et al stated that receptor levels were highest in well-differentiated group of endometrial carcinoma. $\mathrm{Hu} \mathrm{K}^{20}$ et al reported decreased levels of estrogen receptors in both atypical hyperplasia and adenocarcinoma. Teleman $\mathrm{S}^{21}$ et al reported high level of both ER and PR in simple and complex hyperplasias and a significant decrease in atypical hyperplasia. Nyholm $\mathrm{HC}^{22}$ et al stated that adenomatous hyperplasia have high progesterone receptor levels. Guo $\mathrm{Y}^{23}$ et al reported that ER and PR rates in adenocarcinoma were higher than in the normal histological types. Samhita Chakraborty ${ }^{24}$ et al reported increased levels of ER and PR levels in DUB cases.

\section{Conclusion}

An imbalance of the hormones leads to abnormal uterine bleeding and also endometrial carcinoma. In our study ER and PR levels were very high in simple and complex endometrial hyperplasia \& endometrial carcinoma. It was slightly increased in disordered proliferation and irregular shedding and almost normal in secretory and proliferative endometrium. Thus ER and PR levels shown to be increased in endometrial carcinomas have been associated with well differentiated tumor phenotype and treatment options are determined on the basis of their levels. Finally stepwise evidence - based approach to managing menorrhagia is recommended. Medical management is considered first line in the treatment of menorrhagia. Oral contraceptive pills, patches, vaginal rings, cyclic progestins or levonorgestrel IUD may be utilized to regulate menses. When medical management fails, surgical options that may be considered include operative hysteroscopy with endometrial resection, endometrial ablation, uterine artery embolization or hysterectomy.

\section{References}

[1] Coulter A, Bradlow J, Agass M, Martin-Bates C, and Tulloch A. Outcomes of referrals to gynecology outpatient clinics for menstrual problems: An audit of general practice records. Brit J Obstet Gynaecol 1991; 98: 789-96.

[2] Pilli GS, Sethi B, Dhaded AV, Mathur PR. Dysfunctional uterine bleeding (Study of 100 cases). J of Obst and Gyn of India 2002; 52(3): 87-89.

[3] Madiha et al. Pathological findings in hysterectomy specimens of patients presenting with menorrhagia in different age groups. Ann Pak Inst Med Sci Jul - Sep 2011; 7(3):160-2.

[4] Archana Bhosle et al. Evaluation and Histopathological Correlation of Abnormal Uterine Bleeding in Perimenopausal Women. Bombay Hospital Journal, Vol. 52, No. 1, 2010.

[5] Sadia Khan et al. Histopathological Pattern of Endometrium on Diagnostic D and C in Patients with Abnormal Uterine Bleeding. Annals vol 17. No. 2 Apr. - Jun. 2011.

[6] Shazia Riaz et al. Endometrial Pathology by Endometrial Curettage in Menorrhagia in Premenopausal Age Group. J Ayub Med Coll Abbottabad 2010;22(3)

[7] Layla S Abdullah. Histopathological Pattern of Endometrial Sampling Performed for Abnormal Uterine Bleeding. Bahrain Medical Bulletin, Vol. 33, No. 4, December 2011.

[8] Vysotskii MM et al. The pathogenetic basis for using antiestrogens in treating patients with hyperplastic processes of the endometrium in the postmenopause. Akush Ginekol. 1993 ; (6):46-9.

[9] Gorchev G et al. Serum E2 and progesterone levels in patients with atypical hyperplasia and endometrial carcinoma. Akush Ginekol. 1993; 32(2):23-4.

[10] Lepine $\mathbf{J}$ et al. Circulating estrogens in endometrial cancer cases and their relationship with tissue expression of key estrogen biosynthesis and metabolic pathways. J Clin Endocrinol Metab. 2010 Jun; 95(6):2689-98. Epub 2010 Apr 6. 
[11] Mulayim B et al. The Relation of Serum Inhibin B, Estradiol and FSH Levels to Menometrorrhagia in Perimenopausal Women. J Turkish-German Gynecol Assoc, Vol. 9(3); 2008:149-151.

[12] Moen MH, Kahn H, Bjerve KS, Halvorsen TB. Menometrorrhagia in the perimenopause is associated with increased serum estradiol. Maturitas. 2004; 47:151-5.

[13] Choi HY, Lee YB, Kim DS. Histochemical Studies of Human Endometrium with Special Emphasis on Secretory Activity and Ovulation. Yonsei Med J. Dec 1966; 7(1):7-12.

[14] Eddie Moore et al. A Histochemical Study of Endometrial and Aborted Placental Tissue. Journal Of The National Medical Association January, 1962, Vol. 54, No. 131

[15] Dunton C, Baak J, Palazzo J et al. Use of computerized morphometric analyses of endometrial hyperplasias in the prediction of coexistent cancer. Am J Obstet Gynecol 174:1518, 1996

[16] Kendall BS, Ronnett B M, Isacson C et al. Reproducibility of the diagnosis of endometrial hyperplasia, atypical hyperplasia, and well-differentiated carcinoma. Am J Surg Pathol 1998; 22:1012.

[17] Elyzabeth. Simple hyperplasia versus proliferative endometrium: stereological study. J. Bras. Patol. Med. Lab. 2003, vol.39, n.1, pp. 73-79.

[18] Baak JPA. The role of computerized morphometric and cytometric feature analysis in endometrial hyperplasia and cancer prognosis. J. Cell. Bioch. Supplement 23:137-146, 1995.

[19] Spona J et al. Hormone serum levels and hormone receptor contents of endometria in women with normal menstrual cycles and patients bearing endometrial carcinoma. Gynecol Obstet Invest. 1979; 10(2-3):71-80.

[20] $\mathrm{Hu} \mathrm{K}$ et al. Expression of estrogen receptors ERalpha and ERbeta in endometrial hyperplasia and adenocarcinoma. Int J Gynecol Cancer. 2005 May-Jun; 15(3):537-41.

[21] Teleman S et al. An immunohistochemical study of the steroid hormone receptors in endometrial hyperplasia. Rev Med Chir Soc Med Nat Iasi. 1999 Jan-Jun; 103(1-2):138-41.

[22] Nyholm HC et al. Biochemical and immunohistochemical estrogen and progesterone receptors in adenomatous hyperplasia and endometrial carcinoma: correlations with stage and other clinicopathologic features. Am J Obstet Gynecol. 1992 Nov; 167(5):1334-42.

[23] Guo Y et al. Estrogen and progesterone receptors in endometrial carcinoma. Zhonghua Fu Chan Ke Za Zhi. 1997 Jul; 32(7):41821.

[24] Samhita Chakraborty et al. Endometrial hormone receptors in women with dysfunctional uterine bleeding. Archives Of Gynecology And Obstetrics Volume 272, Number 1, 17-22, 2005. 